\title{
Comparison of Modified Blair Incision and Modified Facelift Incision in Parotidectomy
}

\author{
Moo Keon Kim, Yong Bae Ji, Chang Myeon Song, Seung Hwan Lee, \\ Kyung Rae Kim, and Kyung Tae \\ Department of Otorhinolaryngology-Head and Neck Surgery, Hanyang University College of Medicine, Seoul, Korea
}

\author{
이하선 절제술시 절개방법의 비교연구 \\ 김무건 · 지용배 · 송창면 · 이승환 · 김경래 · 태 경 \\ 한양대학교 의과대학 이비인후-두경부외과학교실
}

\author{
Received September 25, 2014 \\ Revised December 1, 2014 \\ Accepted December 16, 2014 \\ Address for correspondence \\ Kyung Tae, MD \\ Department of Otorhinolaryngology- \\ Head and Neck Surgery, \\ Hanyang University \\ College of Medicine, \\ 222-1 Wangsimni-ro, Seongdong-gu, \\ Seoul 133-817, Korea \\ Tel $+82-2-2290-8585$ \\ Fax +82-2-2293-3335 \\ E-mail kytae@hanyang.ac.kr
}

Background and Objectives Modified Blair incision (MBI) and Modified facelift incision (MFI) are mainly used for paroidectomy. MBI can provide a wide surgical view for parotidectomy. MFI was designed for better cosmesis by hiding the incision behind the auricle and hair line. This study was performed to evaluate surgical outcomes, functional and cosmetic results after parotidectomy using MBI and MFI.

Subjects and Method We retrospectively reviewed medical records of 120 patients who underwent parotidectomy from September 2005 to April 2012. Tumor characteristics, operative outcome, and cosmetic outcome according to incision method were investigated. Cosmetic satisfaction was assessed using a questionnaire 12-18 months after surgery.

Results Tumor characteristics such as size, location and pathologic features did not differ between the two groups. The extent of parotidectomy, operation time, amout of drainage, and complications were also not different between the two groups. Cosmetic satisfaction was significantly supeior in the MFI group than that of the MBI group.

Conclusion MFI is superior to MBI for parotidectomy for having similar surgical outcome but better esthetical success compared to MBI.

Korean J Otorhinolaryngol-Head Neck Surg 2015;58(5):337-40

Key Words Modified Blair incision · Modified facelift incision · Parotidectomy $\cdot$ Parotid tumor.

\section{서 론}

두경부 영역에서 발생하는 종양 중 타액선에 발생하는 종양 은 약 $3 \%$ 이며, 타액선 종양의 약 $80 \%$ 는 이하선에서 발생한다. 이하선 절제술은 이하선의 염증성 병변, 양성 종양 및 악성 종양에 대한 수술적 치료가 필요한 경우에 시행하며, 이하선 종양의 수술에 대한 지침은 1903년 Gutierrez에 의해 처음 기 술되었다. ${ }^{1)}$ 이하선 절제술을 위한 절개법으로는 1912년에 Blair에 의해 총검 형태의 절개법인 Blair incision이 소개된 이후로 Modified Blair incision(MBI)이 가장 일반적으로 사
용되어 왔다. ${ }^{1-4)} \mathrm{MBI}$ 는 이주 앞에서부터 시작하여 하악 하연 과 평행하게 주행하는 경부 피부 절개선으로 연결되어 있어 우수한 수술 시야를 제공한다는 장점이 있지만, 절개선이 길 고 경부에 육안상 보이는 반흔을 남긴다는 단점이 있다. 이 단 점의 개선 노력으로 1967년 처음 Modified facelift incision (MFI)이 소개되었고 이는 이개 전방에서 시작하여 수직으로 이주의 경계를 따라 내려가 귓불을 돌아 이개 후방으로 향 한 후 유양돌기 방향으로 상방으로 $2 \mathrm{~cm}$ 정도 진행한 후 모발 선을 따라 하방으로 필요한 만큼 내려가는 절개법이다. MFI 는 $\mathrm{MBI}$ 와 같이 대이개신경의 후방 분지를 보존하기 위하여 탐 
색할 때에도 용이하며, 흥쇄유돌근 회전 피판술 및 이개전방 부 절개선을 위로 연장하면 측두근막을 이용한 수술을 병행 할 수 있다는 점 외에도 $\mathrm{MBI}$ 에 비해 미용적으로 우수성이 보 고되면서 현재 이하선 절제술시 널리 쓰이고 있다. ${ }^{5-7)}$

본 연구에서 저자들은 이하선 절제술에 있어서 $\mathrm{MBI}$ 와 $\mathrm{MFI}$ 의 수술적 적용, 수술 결과 및 합병증, 술 후 환자의 주관적 미 용적 만족도를 비교 분석하여 향후 이하선 절제술 절개방식 선택에 도움을 주고자 하였다.

\section{대상 및 방법}

2005년 9월부터 2012년 4월까지 이하선 종양으로 이하선 절 제술을 시행받았던 환자군 중 술 후 최소 18 개월 이상 추적관 찰하였고 술 후 합병증 평가 및 술 후 미용적 만족도에 대한 설 문이 가능하였던 120 예를 대상군으로 하였다.

이하선 절제술과 동시에 경부 절제술을 시행받았거나 술 후 방사선 치료를 받은 경우, 경부 수술의 과거력이 있는 경우, 이전에 경부 방사선 치료를 받은 경우는 본 연구 대상에서 제 외하였다.

대상 환자들을 절개법에 따라 $\mathrm{MBI}$ 군과 $\mathrm{MFI}$ 군으로 나누 어 성별, 나이, 종양의 크기, 위치, 병리학적 특성을 조사하였 다. 절개법의 선택은 종양의 크기, 위치, 병리학적 특성, 환자 의 미용적 요구 등을 고려하여 결정하였다. 모든 예에서 표층 근건막계를 포함하여 최대한 두껍게 피판을 만들기 위해 노 력하였으며, 대이개신경은 가능한 보존하였다. 술 후 함몰 방
지나 Frey 증후군 예방을 위한 추가 술식은 시행하지 않았다. 수술시간, 배액량, 술 후 합병증으로 조사하였으며, Frey 증 후군은 술 후 12 18개월 사이에 환자의 주관적 증상에 대한 문진 또는 Minor's starch test를 이용하여 평가하였다. 이와 동 시에 미용적 만족도를 설문지를 이용하여 평가하였으며, 미용 적 만족도는 '매우 불만족' 1점부터 '매우 만족'을 5점으로 하 여 1 5점으로 평가하였다.

통계분석은 SPSS version 21(SPSS Inc., Chicago, IL, USA) 을 이용하여 Fisher's exact test와 $\mathrm{t}$-검정을 사용하였으며, 통 계학적 유의 수준은 95\% 이상 $(p$ value< $<.05)$ 으로 하였다.

\section{결 과}

이하선 절제술을 받은 120 예 중 MBI는 57예, MFI는 63예 에서 시행되었고, 평균 연령은 $\mathrm{MBI}$ 군에 비해 $\mathrm{MFI}$ 군에서 유 의하게 낮았으며 $(p<0.001)$, 평균 추적관찰 기간은 $\mathrm{MBI}$ 군에 비해 MFI군이 짧았다 $(p<0.001)$. 남녀비는 두 군 간에 유의 한 차이를 보이지 않았으며 종양의 크기, 종양의 위치에 있어 서도 두 군 간의 유의한 차이는 보이지 않았다(Table 1).

종양의 병리학적 분류상 다형선종이 $\mathrm{MBI}$ 군과 $\mathrm{MFI}$ 군에서 각각 29예(51\%), 33예(52\%)로 가장 많았고 다음으로는 Warthin 종양이 각각 17예(30\%), 15예(24\%)로 많았다(Table 2).

수술 범위에 따라서는 이하선 전절제술, 천엽절제술, 부분 절제술이 $\mathrm{MBI}$ 군에서는 3예(5\%), 6예(11\%), 48예(84\%)가 시행 되었고, MFI군에서는 1예(2\%), 5예(8\%), 57예(90\%)가 시행되

Table 1. Patient demographics and clinicopathologic characteristics of tumor

\begin{tabular}{|c|c|c|c|}
\hline Variable & Modified Blair incision $(n=57)$ & Modified facelift inicision $(n=63)$ & p-value \\
\hline Age (range) & $55.4 \pm 11.8(25-81)$ & $46 \pm 15.3(11-76)$ & $<0.001$ \\
\hline Gender & & & 0.361 \\
\hline Male & $31(56 \%)$ & $28(44 \%)$ & \\
\hline Female & $26(44 \%)$ & $35(56 \%)$ & \\
\hline Mean follow up period (months) & $45.2 \pm 20.7$ & $30.1 \pm 19.2$ & $<0.001$ \\
\hline Tumor size $(\mathrm{cm})$ & $2.4 \pm 1.13$ & $2.3 \pm 0.94$ & 0.477 \\
\hline Tumor location & & & 0.670 \\
\hline Superficial & $52(91 \%)$ & $56(89 \%)$ & \\
\hline Deep & $5(9 \%)$ & $7(11 \%)$ & \\
\hline
\end{tabular}

Table 2. Pathologic types according to incision method

\begin{tabular}{lcc}
\hline \multicolumn{1}{c}{ Pathology } & Modified Blair incision $(\mathrm{n}=57)$ & Modified facelift incision $(\mathrm{n}=63)$ \\
\hline Pleomorphic adenoma & $29(51 \%)$ & $33(52 \%)$ \\
Warthin's tumor & $17(30 \%)$ & $15(24 \%)$ \\
Basal cell adenoma & $2(4 \%)$ & $2(3 \%)$ \\
Mucoepidermoid carcinoma & $0(0 \%)$ & $4(6 \%)$ \\
Adenoid cystic carcinoma & $2(4 \%)$ & $0(0 \%)$ \\
Inflammatory lesion & $4(7 \%)$ & $3(5 \%)$ \\
Others & $3(5 \%)$ & $6(10 \%)$ \\
\hline
\end{tabular}


Comparison of Incision in Parotidectomy I Kim MK, et al.

Table 3. Operation time, amount of drainage and complications after parotidectomy according to incision method

\begin{tabular}{lccc}
\hline \multicolumn{1}{c}{ Variable } & Modified Blair incision $(\mathrm{n}=57)$ & Modified facelift incision $(\mathrm{n}=63)$ & $\mathrm{p}$-value \\
\hline Operation time $(\mathrm{min})$ & $149.4 \pm 52.4$ & $166.3 \pm 46.7$ & 0.062 \\
Amount of drainage $(\mathrm{cc})$ & $68.7 \pm 61.16$ & $87.6 \pm 26.9$ & 0.093 \\
Hematoma (\%) & $0(0)$ & $0(0)$ & $0(0)$ \\
Seroma (\%) & $0(0)$ & & 0.801 \\
Facial nerve palsy (\%) & & $10(16)$ & $0(0)$ \\
$\quad$ Transient & $0(11)$ & $10 / 48(21)$ & 0.189 \\
$\quad$ Permanent & $13 / 39(33)$ & & 0 \\
Frey syndrome $(\%)$ & &
\end{tabular}

Table 4. Cosmetic satisfaction after parotidectomy

\begin{tabular}{lccc}
\hline \multicolumn{1}{c}{ Variable } & Modified Blair incision $(n=57)$ & Modified facelift incision $(n=63)$ & $p$-value \\
\hline Cosmetic satisfaction score & & & $<0.001$ \\
Total & $3.2 \pm 1.1$ & $4.2 \pm 0.8$ & $<0.001$ \\
Male & $3.0 \pm 1.2$ & $4.1 \pm 0.8$ & $<0.001$ \\
Female & $3.5 \pm 0.9$ & $4.2 \pm 0.8$ & $<0.001$ \\
Age $\geq 55$ & $3.0 \pm 1.0$ & $4.2 \pm 0.8$ & $<0.001$ \\
Age $<55$ & $3.4 \pm 1.3$ & $4.1 \pm 0.8$ & \\
\hline
\end{tabular}

었다.

수술시간 및 술 후 배액량은 두 군 간에 통계적으로 유의 한 차이를 보이지 않았으며, 혈종 및 장액종의 발생도 양 군 간 유의한 차이를 보이지 않았다. 영구적 안면신경마비는 양 군 모두 발생하지 않았고, 일시적 안면신경마비는 MBI군과 $\mathrm{MFI}$ 군에서 각 6예(11\%), 10예(16\%)에서 발생하였다. Frey 증후군 검사를 위한 minor's starch test나 증상에 대한 문진이 $\mathrm{MBI}$ 군은 39예, $\mathrm{MFI}$ 군은 48예에서 가능하였는데, 이 중 $\mathrm{MBI}$ 군 은 13예(33.3\%), MFI군은 10예(20.8\%)에서 양성 소견을 보였 고, 두 군 간 유의한 차이는 없었다 $(p=0.189)(T a b l e ~ 3)$. 미용적

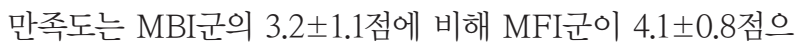
로 유의하게 높았다. 성별에 따라 나누어 분석한 결과에서도 남녀 모두에서 미용적 만족도의 유의한 차이를 보였으며, 55세 를 기준으로 나이에 따라 나누어 분석하였을 때도 MFI군에서 의 미용적 만족도가 MBI군에 비해 유의하게 높았다(Table 4).

\section{고 찰}

본 연구에서 $\mathrm{MFI}$ 와 $\mathrm{MBI}$ 두 접근법 모두 양성 종양과 악성 종양 절제에 적용할 수 있었으며, 이하선 부분절제술뿐 아니 라 이하선 전절제 또한 모두 가능하였다. 이는 경부절제술을 함께 시행하는 경우는 경부절제술 절개와 연장이 가능한 $\mathrm{MBI}$ 법이 다소 유리한 면이 있지만 이하선 절제를 위한 수술 시야 에 있어서는 MFI가 MBI와 비교하여 큰 차이 없이 시행 가능 하다는 것을 시사한다 할 수 있다. 이와 관련하여 Upile 등 ${ }^{8}$ 은 사체 연구를 통해 안면거상 접근법(facelift approach)으로
이하선 절제에 필요한 모든 부위를 확인할 수 있다고 하였다. 또한 본 연구에서는 두 군 간 종양 크기 및 조직 병리 등의 기 타 수술 결과에 있어서도 유의한 차이를 보이지 않았는데, 이 는 위에서 언급했듯이 두 절개법 간의 수술 시야에 큰 차이가 없어 종양의 크기나 병리학적 특성과 상관없이 절개법을 선택 할 수 있음을 시사한다.

이하선 종양의 수술시간 및 술 후 배액량에 대해 본 연구 에서는 MFI가 MBI에 비해 수술시간이 다소 길고, 배액량이 약간 많은 경향을 보였으나 통계적으로 유의한 차이를 보이지 는 않았다. 이는 $\mathrm{MFI}$ 와 $\mathrm{MBI}$ 간의 수술시간 및 배액량에 있 어서 통계적으로 유의한 차이가 없다고 보고했던 이전의 연 구들과 유사하였다. ${ }^{910)}$

두 절개법 간의 합병증에 대한 비교에 있어서 장액종, 혈종, 피부괴사 등의 수술 부위 문제와 안면신경마비 및 Frey 증후 군은 두 군 간에 비슷하거나 $\mathrm{MFI}$ 가 $\mathrm{MBI}$ 에 비해 더 좋은 결 과를 보인다는 보고들이 있는데, ${ }^{10-12)}$ 본 연구에서도 안면신 경 마비를 포함한 합병증 발생에서는 두 군 간에 유의한 차이 를 보이지 않았다.

Frey 증후군의 병리기전은 이하선에 분포하는 부교감신경 이 이하선 수술 후에 안면의 한선과 주위의 혈관에 분포하는 교감신경으로 비정상적으로 연결되면서 발생하여 저작시 발 한, 홍조, 동통 등을 유발하는 것으로 알려져 있다. 이를 예방 하기 위해 피부피판을 두껍게 하는 것과 수술 범위를 최소화 하는 것이 가장 중요하게 여겨지고, 그 외에 흥쇄유돌근 피판, 표층근건막계 피판, 인공보철물의 삽입 등을 이용한 방법을 고려할 수 있다. ${ }^{6,12,13)}$ 
이하선 절제술에서 절개법에 따른 미용적 만족도에 관한 몇몇 보고들이 있었으나 다소 상반된 결과가 보고된 바 있다. 이전의 몇몇 연구에서 $\mathrm{MFI}$ 가 미용적 만족도에 있어서 $\mathrm{MBI}$ 보다 우수하다는 보고가 있었으나, ${ }^{12,14}$ 일부 연구에서는 오히 려 $\mathrm{MBI}$ 군에서 미용적 만족도가 더 좋았다고 보고하기도 하 였다. ${ }^{11)}$ 본 연구에서는 MFI군에서 유의하게 미용적 만족도 가 좋았고, 전체 환자군에서뿐 아니라 성별 및 나이에 따라 각각을 나누어 비교해 보았을 때도 각각의 모든 군에서 $\mathrm{MFI}$ 의 미용적 만족도가 $\mathrm{MBI}$ 보다 유의하게 높은 결과를 나타냈 다. 이는 $\mathrm{MFI}$ 를 이용한 이하선 절제술이 절개선을 이개와 모 발선 속으로 감출 수 있기 때문으로 사료된다.

본 연구의 한계점으로 후향적 연구의 특성상 절개법의 선택 이 무작위 배정되지 않았기 때문에 선택상의 오류가 있었을 수 있으며, 최근에 $\mathrm{MFI}$ 절개법의 적용이 늘어나면서 $\mathrm{MFI}$ 군에서 추적관찰 기간이 $\mathrm{MBI}$ 군에 비해 짧으며, 두 군 간 연령의 차이 가 미용적 만족도에 대한 결과에 영향을 미칠 수 있다는 점이 다. 하지만 연령군에 따른 분석에서도 MFI군에서 미용적 만 족도가 높았던 것은 연령과 상관없이 MFI가 미용적으로 우수 하다는 것을 시사한다고 하겠다.

결론적으로 이하선 절제술시 $\mathrm{MFI}$ 와 $\mathrm{MBI}$ 두 절개법은 비 슷한 수술 결과를 보이지만, $\mathrm{MFI}$ 절개법이 환자의 주관적 미 용 만족도가 높기 때문에, 이하선 종양의 크기, 위치, 성별이나 연령에 상관없이 적용할 수 있는 우수한 절개법이라 사료된다.

\section{REFERENCES}

1) Yong CY, Ho CY, Chou SJ, Fang CY, Lin KC. Modified facelift incision approach in benign tumor of infraauricular region-a case report. Taiwan J Oral Maxillofac Surg 2013;24:58-65.

2) Bova R, Saylor A, Coman WB. Parotidectomy: review of treatment and outcomes. ANZ J Surg 2004;74(7):563-8.

3) Grover N, D'Souza A. Facelift approach for parotidectomy: an evolving aesthetic technique. Otolaryngol Head Neck Surg 2013;148 (4):548-56.

4) Tae K, Lee HS, Hong DK, Park HK, Cho SH, Lee SH, et al. Partial parotidectomy as a conservative procedure for the parotid tumor. Korean J Otolaryngol-Head Neck Surg 2003;46(7):592-7.

5) Bozzetti A, Biglioli F, Salvato G, Brusati R. Technical refinements in surgical treatment of benign parotid tumours. J Craniomaxillofac Surg 1999;27(5):289-93.

6) Park BJ. Parotidectomy: surgical treatment for the benign parotid tumor. Korean J Otorhinolaryngol-Head Neck Surg 2008;51(3):212-6.

7) Jost G, Guenon P, Gentil S. Parotidectomy: a plastic approach. Aesthetic Plast Surg 1999;23(1):1-4.

8) Upile T, Jerjes WK, Nouraei SA, Grant W, Singh S, Sudhoff H, et al. Further anatomical approaches to parotid surgery. Eur Arch Otorhinolaryngol 2010;267(5):793-800.

9) Terris DJ, Tuffo KM, Fee WE Jr. Modified facelift incision for parotidectomy. J Laryngol Otol 1994;108(7):574-8.

10) Lin TC, Chen PR, Wen YH, Chou YF. Intra-auricular modification of facelift incision with sternocleidomastoid flap--a cosmetic approach for parotidectomy: how we do it. Clin Otolaryngol 2011;36(4):375-9.

11) Wasson J, Karim H, Yeo J, Panesar J. Cervicomastoidfacial versus modified facelift incision for parotid surgery: a patient feedback comparison. Ann R Coll Surg Engl 2010;92(1):40-3.

12) Lee SY, Koh YW, Kim BG, Hong HJ, Jeong JH, Choi EC. The extended indication of parotidectomy using the modified facelift incision in benign lesions: retrospective analysis of a single institution. World J Surg 2011;35(10):2228-37.

13) Chamisa I. Frey's syndrome--unusually long delayed clinical onset post-parotidectomy: a case report. Pan Afr Med J 2010;5:1.

14) Bianchi B, Ferri A, Ferrari S, Copelli C, Sesenna E. Improving esthetic results in benign parotid surgery: statistical evaluation of facelift approach, sternocleidomastoid flap, and superficial musculoaponeurotic system flap application. J Oral Maxillofac Surg 2011;69(4):1235-41. 